\title{
A New Approach to Myocardial Revascularization in Patients with Severe Carotid Lesions: Simultaneous Cardiopulmonary Bypass and Local Carotid Endarterectomy
}

\section{Melike Elif Teker*}

Biruni University, Istanbul, Turkey

\begin{abstract}
Aim: In the present study, we aimed to present the retrospective outcomes of the patients who underwent carotid endarterectomy under local anesthesia followed by cardiopulmonary bypass under general anesthesia during the same session.

Material and methods: 52 patients ( 36 male, 16 female patients; mean age was $69.0 \pm 8.5$ years: range 42 to 75 years) with carotid lesions underwent carotid endarterectomy under local anesthesia and simultaneous cardiopulmonary bypass between $1^{\text {st }}$ March 2015 and $1^{\text {st }}$ March 2016 in our center. This study involved patients with myocardial revascularization and $80 \%$ or more carotid stenosis (with or without contralateral disease). Preoperative, preoperative and postoperative characteristics of the patients were retrospectively analyzed.

Results: Operative mortality rate was $1.9 \%$ with one patient. Early postoperative revision was performed in 3 patients $(5.7 \%)$ bleeding. Postoperative atrial fibrillation developed in 6 patients $(11.5 \%)$. There was no cerebrovasculary accident postoperatively.

Conclusion: The incidence of coronary and carotid artery disease coexistence is not too low. The combined approach increases the stroke and mortality rate by using general anesthesia in the procedure, although the odds of complications appearing to reduce the duration of hospitalization with the performance of a single seansta procedure. In this study, we reported that local carotid artery intervention and simultaneous coronary artery bypass surgery reduced the stroke risk and mortality rates.
\end{abstract}

Keywords: Combined treatment; Local anesthesia; Carotid endarterectomy; Cardiopulmonary bypass

\section{Introduction}

Despite the advances in the cardiopulmonary bypass, stroke that may develop during or after the intervention continues to be an important cause of morbidity and mortality. It was reported that the risk of stroke during coronary artery bypass increases to $8 \%$ at the ages of $80 \mathrm{~s}$ from $0.5 \%$ in $50 \mathrm{~s}$. There are close relationships between coronary artery disease and carotid stenosis, and between critical carotid stenosis and stroke [1].

Debates still continue on the timing of cardiopulmonary bypass and planned carotid endarterectomy in patients with coronary artery disease and severe carotid stenosis. The first simultaneous intervention was described by Bernard et al. [2] and Mackey et al. [3] suggested three different ways for coronary artery disease surgery in terms of sequence and timing of the surgery. Those are simultaneous, staged and reverse-staged (coronary surgery followed by carotid endarterectomy) approaches. However currently debates still continue and there is no consensus on these approaches yet. There are concerns that the cerebral blood flow will decrease in the simultaneous approach. Many surgeons are reluctant to perform carotid endarterectomy first, worrying that myocardial infarction may occur during the operation. On the other hand, performing cardiopulmonary bypass first has been reported to increase the stroke rates [4].

Since operations requiring cardiopulmonary bypass are performed under general anesthesia, carotid endarterectomy surgery with simultaneous cardiopulmonary bypass are also performed under general anesthesia. Some publications reported that interventions under general anesthesia increase the rates of stroke and death [5].

In this retrospective study, we aimed to present the outcomes of the patients who underwent carotid endarterectomy under local anesthesia followed by cardiopulmonary bypass under general anesthesia during the same session.

\section{Material and Methods}

In this retrospectively study, patients who underwent carotid endarterectomy under local anesthesia and simultaneous cardiopulmonary bypass for coronary artery disease in the same season in our institute between March 2015 and March 2016 in our center were included.

There were 52 patients, 36 male (69\%), 16 female (31\%); and mean age was $69.0 \pm 8.5$ years (42 to 75 years). Exclusion criteria were as follows: emergency, off-pump surgery, deep hypothermic cardiopulmonary bypass, myocardial infarction, concomitant surgery (valve replacement, or aortic root replacement). 23 had vertigo (44.2\%), 19 had syncope (36.5\%) and 16 had transient ischemic attack (31\%) (TIA). One patient had bilateral carotid stenosis (1.9\%). Preoperative characteristics of the patients are shown in Table 1.

All patients underwent preoperative ultrasonic diagnostics, digital

*Corresponding authors: Melike Elif Teker, Biruni University, Istanbul, Turkey, Tel: 08508111276; E-mail: eteker@birni.edu.tr

Received May 12, 2017; Accepted June 02, 2017; Published June 05, 2017

Citation: Teker ME (2017) A New Approach to Myocardial Revascularization in Patients with Severe Carotid Lesions: Simultaneous Cardiopulmonary Bypass and Local Carotid Endarterectomy. J Cardiovasc Dis Diagn 5: 281. doi: 10.4172/23299517.1000281

Copyright: $\odot 2017$ Teker ME. This is an open-access article distributed under the terms of the Creative Commons Attribution License, which permits unrestricted use, distribution, and reproduction in any medium, provided the original author and source are credited. 
substraction angiography, neurological examination and cardiac catheterization. The principal indication was the need for myocardial revascularization, and symptomatic or asymptomatic carotid stenosis of $70 \%$ diameter reduction or more (with or without contralateral disease) (Table 2).

The clinical worksheet list was used to collect the patients demographic information (age, gender), past history with regard to myocardial infarction, vertigo, syncope and transient ischemic attack (TIA) in Table 3.

\section{Surgical Technique}

All surgical procedures were performed by the same surgical team. On supine position, and under local anesthesia with Marcaine $5 \%$ plus Priloc $2 \%$, a vertical incision was made along the edge of the

\begin{tabular}{|c|c|c|}
\hline Demographic Data & Number & Percent \\
\hline The average age (yrs) & $69 \pm 8.5$ & \\
\hline Woman/Man & $16 / 36$ & $31 / 69$ \\
\hline Family history & 5 & $9.60 \%$ \\
\hline Hypertension & 30 & $57.70 \%$ \\
\hline $\mathrm{KOAH}$ & 35 & $67.30 \%$ \\
\hline Smoking & 35 & $67.30 \%$ \\
\hline Hyperlipidemia & 33 & $63.50 \%$ \\
\hline Diabetes Mellitus & 13 & $25 \%$ \\
\hline Peripheral arterial disease & 35 & $67.30 \%$ \\
\hline Coronary artery occlusion & 28 & \\
\hline Main coronary artery & 0 & \\
\hline Single-vessel lesion & 3 & \\
\hline Two vascular lesion & 4 & \\
\hline Three vascular lesion & 13 & \\
\hline Four vascular lesion & 8 & \\
\hline TIA & 16 & $31 \%$ \\
\hline Vertigo & 23 & $44.20 \%$ \\
\hline Syncope & 19 & $36.50 \%$ \\
\hline History of epilepsy & 3 & $5.70 \%$ \\
\hline
\end{tabular}

Table 1: The demographic data of patients.

\begin{tabular}{|c|c|c|}
\hline Distribution of patients & Number & Percent \\
\hline Right internal carotid & 32 & $61.50 \%$ \\
\hline Left internal carotid & 19 & $36.50 \%$ \\
\hline Bilateral Carotid & 1 & $1.90 \%$ \\
\hline
\end{tabular}

Table 2: The distribution of patients with carotid artery stenoses rates and challenges.

\begin{tabular}{|c|c|}
\hline Intraoperative Data & Number \\
\hline Cardiopulmonary bypass time $(\mathrm{dk})$ & $38.5 \pm 15.2$ \\
\hline Cross clamp time $(\mathrm{dk})$ & $18.6 \pm 5.7$ \\
\hline Carotid clamping time $(\mathrm{dk})$ & $11 \pm 3.7$ \\
\hline
\end{tabular}

Table 3: Intraoperative data.

\begin{tabular}{|c|c|c|}
\hline Postoperative data & Number & Percent \\
\hline Mediastinal bleeding & 3 & $5.70 \%$ \\
\hline Arrhythmia & 6 & $11.50 \%$ \\
\hline Atrial fibrillation & 6 & $11.50 \%$ \\
\hline Stroke temporary/permanent & 0 & 0 \\
\hline Inotropic requirement & 8 & $15.30 \%$ \\
\hline ICU length of stay (hour) & $14.9 \pm 7.4$ hour & \\
\hline The length of hospital stay (days) & $5.2 \pm 1.7$ day & \\
\hline Ekxitus & 1 & $1.90 \%$ \\
\hline
\end{tabular}

Table 4: Postoperative data. sternocleidomastoid muscle for carotid endarterectomy. The carotid artery was explored. The common carotid artery (CCA), external carotid artery (ECA) and internal carotid artery (ICA) were identified, followed by administration of intravenous heparin at a dose of $50 \mathrm{IU} /$ $\mathrm{kg}$. Clamps were applied to the common carotid artery, external carotid artery and internal carotid artery, and a longitudinal incision was made from the CCA to the ICA. Carotid endarterectomy was performed using an intraluminal shunt (Flash Med S.A. ${ }^{\circledR}$ ) in all patients. The carotid artery clamping took $11 \pm 3.7$ minutes on average. The arteriotomy was closed primarily in 40 patients with an internal carotid diameter of 5 $\mathrm{mm}$ or above, and great saphenous venous or Dacron patch was used in 12 others.

After this procedure, the subcutaneous and cutaneous tissues were not closed until the $\mathrm{CABG}$ procedure was completed and after weaning from the CPB. Tamponation was performed. Then a median incision and sternotomy was performed under general anesthesia. Grafts (great saphenous vein, left internal mamaryan artery) were harvested for use in anastomosis. A standard cannulation was performed. Patients were cooled to 32 degrees and cardiopulmonary bypass (CPB) starded. Cardiac arrest with antegrade blood cardioplegia was performed with aortic root cannula under aortic cross clamp. Distal anastomoses were performed. The mean number of grafts per patient was 3. In all patients, proximal anastomoses were performed with side clamp during the $\mathrm{CPB}$. Following removal of the side clamp and weaning from the CPB, firstly the chest and then the carotid area were closed. A penrose drainage tubing (NULIFE ${ }^{\circledast}$ ) to prevent pressure due to a possible haematoma on the carotid artery in all patients. The intraoperative data of the patients are shown in Table 3. The pat ients were transferred to the intensive care unit after the operation. During the postoperative period, Enoxaparin $2 \times 0.6 \mathrm{cc}$, Clopidogrel $1 \times 75 \mathrm{mg}$ and Acetylsalicylic acid (ASA) 1 $\times 100 \mathrm{mg}$ was administered. Enoxaparin was given during the first 3 postoperative days. Following discharge, Clopidogrel and ASA were used as antiaggregant agents. Patients were discharged on the average postoperative $5^{\text {th }}$ day.

\section{Statistics}

All statistics were performed using SPSS 15.0 for Windows (SPSS, Inc., Chicago, IL, USA). Normally-distributed continuous variables were expressed as mean \pm standard deviation (SD) and variables without a normal distribution were expressed as median and ranges. Categorical variables were expressed as frequencies and percentages.

\section{Results}

Postoperative 30-day observations were made. One (1.9\%) of the patients died later due to low cardiac output on postoperative $5^{\text {th }}$ day. Postoperative atrial fibrillation developed in $6(11.5 \%)$ patients, and treated with intravenous amiodarone infusion. No major or minor cerebrovasculary event was observed. In 8 (15.3\%) patients, dopamine and adrenalin were administered in the intensive care unit due to low cardiac output. Three (5.7\%) patients were revised due to postoperative bleeding. The mean length of stay in the intensive care unit was $14.9 \pm$ 7.4 hours, duration of ventilation was $7 \pm 1.5$ and length of stay in the hospital was $5.2 \pm 1.7$ days. The post-operative complications and data are shown in Table 4.

\section{Discussion}

Decreased cerebral blood flow during cardiopulmonary bypass is one of the factors causing postoperative ischemia. In fact, non-pulsatile flow and unstable arterial pressure that may develop during cardiopulmonary bypass are triggering factors of neurological events [6]. 
Carotid stenosis is an important risk factor for stroke since it increases the risk of cerebrovascular events by $10 \%$ in patients who undergo cardiopulmonary bypass surgery $[3,7]$. It was reported that, carotid stenosis above $70 \%$ was detected in $10 \%$, stenosis between $50 \%$ and $70 \%$ in $9 \%$ to $22 \%$, and stenosis under $50 \%$ in $80 \%$ to $91 \%$ of all patients for whom cardiopulmonary bypass was planned [8]. Considering that carotid artery stenosis is related with stroke, we performed carotid doppler ultrasonography and included those with stenosis of $70 \%$ in our study.

Also, due to the association of coronary artery disease and carotid atherosclerotic stenosis, different centers try different approaches. The main aim is to reduce the incidence of postoperative stroke in all approaches (i.e. staged, combined or simultaneous hybrid revascularization) [9].

Debates still continue on how the best approach to the combined operation, which was firstly performed by Bernhard et al. [2], should be [10]. Many studies have been conducted on this which generally gave similar results in terms of cerebrovascular events, myocardial infarction and mortality. In their meta-analysis for simultaneous and staged surgical treatment, Sharma et al. [4] observed equivalent mortality and stroke profiles, and reported that some specific characteristics of patients and atherosclerotic disease morphology are more important

Another study with a multi-center design demonstrated that the rate of stroke increased by $10 \%$ in patients who underwent cardiopulmonary bypass followed by carotid endarterectomy, and based on this information, found that this rate is significantly higher compared to the combined surgery [11]. Yildirim et al. [12] reported that carotid endarterectomy and cardiopulmonary surgery under cardiopulmonary bypass is a safe method with acceptable mortality and morbidity rates. In their retrospective study, Byrne et al. [5] reported low mortality and morbidity rates in 758 patients with hemodynamically significant but asymptomatic carotid stenosis who underwent combined surgery. We thought that the combined operation would protect the patient from complications such as stroke and mild and the patient underwent carotid endarterectomy and coronary bypass in the same session.

Gopaldas et al. [13] reported that they did not observe any significant difference in terms of stroke and mortality between simultaneous and staged carotid endarterectomy, however there was a significant difference in terms of hospital costs in favor of the group that underwent simultaneous surgery.

Advantages such as shorter hospitalization, lower cost, acceptable early mortality and morbidity, and reduced risk of stroke in the long term have been reported for the combined surgical approach [14]. In the light of the studies and results, we used the combined surgical technique within the same session for cardiopulmonary and carotid artery stenosis.

Carotid artery $[15,16]$ and coronary bypass surgery [17] have acceptable mortality and morbidity rates. So that the same seansta continues to be the result of the debate whether or not to intervene.

Since cardiopulmonary bypass is performed under general anesthesia, the combination of carotid endarterectomy and cardiopulmonary bypass is also performed under general anesthesia. Although we performed the combined surgery method for carotid endarterectomy routinely under general anesthesia in previous years, now we prefer local anesthesia. This opens the veil drawn on the patient's neurological functions under general anesthesia, facilitating the follow-up [18]. So, this method allows us to observe the patient during carotid endarterectomy and to diagnose neurological deficits that may develop during the operation. Intraoperative neurological examination is the most reliable method to determine the suitability of cerebral perfusion during application of a cross-clamp to the carotid artery. Evaluation of consciousness and speech and examination of the grip strength of the contralateral hand provide very important information [19]. We performed carotid endarterectomy under local anesthesia in the combined treatment, allowing us to observe the prebypass neurological functions of the patients.

Although the combined approach may seem to reduce the length of stay in the hospital and the cost in several studies due to performance of the procedure in a single session, it has been reported that using general anesthesia in the procedure increased the rates of stroke and death $[20,21]$. We performed the procedure under local anesthesia to minimize neurological deficits in our patients.

In this procedure (simultaneous cardiopulmonary bypass and local carotid endarterectomy), patients should be completely cooperative since they also have severe coronary artery disease. This procedure allows us to avoid undesirable outcomes that may lead to anxiety and severe intraoperative myocardial infarction [22]. Through this procedure, we have protected our patients from these complications.

Using a carotid shunt helps to perform a safer surgical intervention [23-25]. There are disadvantages such as particle embolization associated with carotid shunt use [26]. We used shunt in all of our patients in our clinic.

\section{Conclusion}

The incidence of coronary and carotid artery disease coexistence is not too low. The combined approach increases the stroke and mortality rate by using general anesthesia in the procedure, although the odds of complications appearing to reduce the duration of hospitalization with the performance of a single seansta procedure However, local carotid artery surgery and concomitant coronary bypass reduced mortality and minimized hospitalization. Also, other advantages such as shorter hospitalization, lower cost in the long term have been reported for the combined surgical approach.

Retrospective design of the study and the inclusion of limited number of the cases were the main limitations.

\section{References}

1. Merie C, Kober L, Olsen PS, Andersson C, Jensen JS, et al. (2012) Risk of stroke after coronary artery bypass grafting: Effect of age and comorbidities. Stroke 43: 38-43.

2. Bernhard VM, Johnson WD, Peterson JJ (1972) Carotid artery stenosis: Association with surgery for coronary artery disease. Arch Surgery 105: 837-40.

3. Mackey WC (1998) Carotid and coronary disease: Staged or simultaneous management?. In seminars in vascular surgery 11: 36-40.

4. Sharma V, Deo SV, Park SJ, Joyce LD (2014) Meta-analysis of staged versus combined carotid endarterectomy and coronary artery bypass grafting. Ann Thorac Surg 97: 102-109.

5. Byrne J, Darling RC, Roddy SP, Mehta M, Paty PSK,et al. (2006) Combined carotid endarterectomy and coronary artery bypass grafting in patients with asymptomatic high-grade stenoses: An analysis of 758 procedures. J Vasc Surg 44: 67-72.

6. Dylewski M, Canver CC, Chanda J, Darling RC 3rd, Shah DM (2001) Coronary artery bypass combined with bilateral carotid endarterectomy. Ann Thorac Surg 71: $777-781$.

7. Oakes DA, Eichenbaum KD (2014) Perioperative management of combined carotid and coronary artery bypass grafting procedures. Anesthesiol Clin 32 699-721. 
Citation: Teker ME (2017) A New Approach to Myocardial Revascularization in Patients with Severe Carotid Lesions: Simultaneous Cardiopulmonary Bypass and Local Carotid Endarterectomy. J Cardiovasc Dis Diagn 5: 281. doi: 10.4172/2329-9517.1000281

Page 4 of 4

8. Venkatachalam S, Shishehbor MH (2011) Management of carotid disease in patients undergoing coronary artery bypass surgery: Is it time to change our approach? Curr Opin Cardiol 26: 480-487.

9. Chiariello L, Tomai F, Zeitani J, Versaci F (2006) Simultaneous hybrid revascularization by carotid stenting and coronary artery bypass grafting. Ann Thorac Surg 81: 1883-1885.

10. Çimen S, Ozkul V, Ozay B, Ketenci B, Guney M, et al. (2005) Carotis and coronary artery disease: Is concomitant operation necessary?. Turki J Thorac Cardiovasc Surg 13: 6-9.

11. Moore WS, Barnett HJ, Beebe HG, Bernstein EF, Brener BJ, et al. (1995) Guidelines for carotid endarterectomy: A multidisciplinary consensus statement from the Ad Hoc committee. American Heart Association. Circulation 91: 566-579.

12. Yildirim T, Koksal C, Kiniklioglu H, Arsan S (2005) Simultaneous carotid endarterectomy and myocardial revascularization by using cardiopulmonary bypass for both procedures. Acta Cardiol 60:575-579.

13. Gopaldas RR, Chu D, Dao TK, Huh J, LeMaire SA, et al. (2011) Staged versus synchronous carotid endarterectomy and coronary artery bypass grafting: Analysis of 10-year nationwide outcomes. Ann Thorac Surg 91: 1323-1329.

14. Gaudino M, Glieca F, Alessandrini F, Cellini C, Luciani N, et al. (1999) Individualized surgical strategy for the reduction of stroke in pa-tients undergoing CABG. Ann Thorac Surg 67: 1246-1253.

15. Whittmore AD, Mannick JA (1987) Surgical treatment of carotid disease in patients with neurologic deficits. J Vasc Surg 5: 910-913.

16. Özdemir N, Nüsser CJ (1995) Surgical treatment and results of asymptomatic carotid stenosis. J Vasc Surg 4: 60-63.

17. Muneretto C, Bisleri G, Negri A, Manfredi J, Metra M, et al. (2003) Off pump coronary artery bypass surgery technique for total arterial myocardial revascularization: A prospective randomized study. Ann Thorac Surg 76 778-783.

18. Rerkasem K, Bond R, Rothwell PM (2008) Local versus general anaesthesia for carotid endarterectomy. Cochrane Database Syst Rev 8: CD000126.

19. Morgan GE, Mikhail MS, Butterworth JF, Mackey DC, Wasnick JD (2013) Anesthesia for cardiovascular surgery. Clinical Anesthesiology (5 edn) Newyork Lange Medical Books/McGraw-Hill USA 435-487.

20. Daily PO, Freeman RK, Dembitsky WP, Adamson RM, Moreno-Cabral RJ, et al (1996) Cost reduction by combined carotid endarterectomy and coronary artery bypass grafting. J Thorac Cardiovasc Surg 111: 1185-1192.

21. Khaitan L, Sutter FP, Goldman SM, Chamogeorgakis T, Ann C Wertan M, et al. (2000) Simultaneous carotid endarterectomy and coronary revascularization. Ann Thorac Surg 69: 421-424.

22. Cuhruk H (2010) Major vascular surgery anesthesia. Anesthesia, Intensive Care, Pain. (1stedn) MN Medical \& Nobel. 703-829.

23. Ozatik MA, Gol MK, Fansa I, Uncu H, Kucuker SA, et al. (2005) Risk factors following coronary artery bypass operations. J Card Surg 20: 52-57.

24. Akins CW, Hilgenberg AD, Vlahakes GJ, Madsen JC, MacGillivray TE, et al (2005) Late results of combined carotid and coronary surgery using actua versus actuarial methodology. Ann Thorac Surg 80: 2091-2097.

25. Cinar B, Goksel OS, Karatepe C, Kut S, Aydogan H, et al. (2004) Is routine intravascular shunting necessary for carotid endarterectomy in patients with contralateral occlusion? A review of 5-year experience of carotid endarterectomy with local anaesthesia. Eur J Vasc Endovasc Surg 28: 494-499.

26. Harada RN, Comerota AJ, Good GM, Hashemi HA, Hulihan JF (1995) Stump pressure, electro encephalographic changes, and the contralateral carotid artery another look at selective shunting. Am J Surg 170: 148-153. 